\title{
CONSUMIDOR Y DOBLE FINALIDAD EN LA UTILIZACIÓN DEL BIEN*
}

\author{
Alfredo Ferrante \\ Universidad Alberto Hurtado
}

\section{INTRODUCCIÓN}

Indudablemente el consumidor está tutelado frente a la redacción de cláusulas abusivas. $\mathrm{Al}$ margen de la interpretación de los efectos de la nulidad en ámbito chileno ${ }^{1}$, es importante destacar que en España se ha consolidado la abusividad de la llamada cláusula sue$l^{2}$ en el contrato de préstamo y de sus efectos. A pesardeque el TribunalSupremo se había decantado por conceder los efectos restitutorios solo desde la fecha de la sentencia ${ }^{3}$, ha tenido que rea-

* La presente publicación se enmarca en le proyecto FONDECYT No 1171251 , del cual el autor es investigador responsable.

${ }^{1}$ Cfr. art. 16A y 16B Ley 19.946. Sobre el punto v.gr. véase BARAONA GONZÁlez (2015).

${ }^{2}$ Esta cláusula normalmente se incluye en las condiciones generales de los contratos de préstamo con interés variable. El banco establece que la tasa de interés de referencia no puede caer por debajo de un cierto umbral ("suelo") y por ello establece el bloqueo de un cobro mínimo de interés, independiente de que la tasa efectivamente baje, por ejemplo, debido a la fluctuación de la referencia del cálculo (como sucede con el EURIBOR).

${ }^{3}$ Esta era la postura del Tribunal Supremo español adoptado tanto en caso de acción colectiva (STS No 41/2013, de 9 de mayo), como individual STS, pleno, $\mathrm{N}^{\circ} 138 / 2015$, de 24 de marzo, (RJ 2015/845); STS, pleno, No 139/2015, de 25 de marzo, (RJ 2015/735). lizar un revirement ${ }^{4}$, debido al mandato impuesto por el Tribunal Superior de Justicia de la Unión Europea ${ }^{5}$ que lo define retroactivamente desde el momento de la celebración del contrato; aparejando la necesidad de regular el fenómeno frente a la masiva petición de restituciones dineraria por parte del consumidor ${ }^{6}$.

En este contexto, por lo tanto, enmarcar o no al contratante en el estado de consumidor tiene importantes consecuencias prácticas, ya que significa abrir la puerta a la restitución de importantes cantidades cobradas en ex-

${ }^{4}$ Así se modifica la doctrina anterior fijada por el Tribunal Supremo mediante: STS N ${ }^{\circ} 123 /$ 2017, de 24 de febrero (RJ 2017/602), también véase STS No 248/2017, de 20 de abril (RJ 2017/ 1559), STS $\mathrm{N}^{\mathrm{o}} 171 / 2017$, de 9 de marzo (RJ 2017/977).

${ }^{5}$ Esto ocurre mediante la STJUE 21 de diciembre de 2016, asuntos acumulados C-154/ 15, C-307/15 y C-308/15. La bibliografía sobre el tema es vastísima, por todos v.gr. CÁmara LAPUENTE (2017).

${ }^{6} \mathrm{~A}$ estos efectos se ha dictado el real decreto-ley 1/2017, de 20 de enero, de medidas urgentes de protección de consumidores en materia de cláusulas suelo $\left(B O E, \mathrm{~N}^{\circ} 18\right.$, de 21 de enero de 2017). Este ha sido recientemente complementado por el real decreto 536/2017, de 26 de mayo, por el que se crea y regula la Comisión de Seguimiento, Control y Evaluación prevista en el real decreto-ley 1/2017 (BOE, $\mathrm{N}^{\mathrm{O}} 126$, de 27 de mayo de 2017). 
ceso en los contratos de préstamos celebrados, incluso, hace décadas.

Así es el caso de Bernardino que, en junio de 2005, celebró con el banco un contrato de préstamo con garantía hipotecaria pidiendo las correspondientes devoluciones a raíz de la nulidad de la cláusula suelo ${ }^{7}$. Al margen de la abusividad de la cláusula lo que aquí se quiere destacar es que el Tribunal Supremo español ${ }^{8}$ deniega las restituciones al no considerarlo consumidor, confirmando la sentencia de apelación ${ }^{9}$ y dejando sin efecto la sentencia de primera instancia ${ }^{10}$, que sí lo había considerado tal.

El problema se da, ya que la utilización del bien adquirido se destinaba en parte a uso personal y en parte no. Efectivamente, Bernardino realizaba 274 su actividad profesional en la misma finca en la cual vivía. Esta tenía de varias hectáreas que explotaba con actividad de ganadería y en la cual construyó dos inmuebles, uno destinado a vivienda habitual y otro que dedicaba a arrendamiento de habitaciones. En definitiva, el contratante había solicitado un préstamo para la reconstrucción de ambos inmuebles, es decir, para una doble finalidad, una personal y otra profesional. La sentencia se pronuncia expresamente sobre los criterios que permiten identificar el consumidor cuando

${ }^{7}$ En el caso concreto había una cláusula suelo con límites fijados en el 3\% y una cláusula techo del 10\%, que era variable con respecto al taso del EURIBOR más un punto porcentual.

${ }^{8}$ STS, sala $1^{\text {a }}$, No $224 / 2017$, de 5 de abril de 2017 (JUR 2017/86709).

${ }^{9}$ SAP Vizcaya, sec. $4^{\text {a }}$, No 477/2014, de 30 de julio (JUR 2014/ 267776).

${ }_{10}$ JPI mercantil, $\mathrm{N}^{\circ}$ 1, Bilbao, $\mathrm{N}^{\circ} 249$ / 2013, de 10 de diciembre (AC 2014/175).

el sujeto utilice el bien no solo con un fin particular.

$\mathrm{Al}$ margen de que en el caso de quo se niega el estado de consumidor al considerarse
"probado que el destino profe- sional del préstamo no fue mar- ginal oresidual, sino quefue pre- ponderante" 11

al quererse reparar y acondicionar todo un edificio para dedicarlo a negocio de alquiler inmobiliario; es importante, antes que todo, destacar que se decanta en un criterio general pro consumatore. En efecto, se parte de una presunción de estado de consumidor ya que se constata:

"cuando no resulte acreditado claramente que un contrato se ha llevado a cabo de manera exclusiva con un propósito ya sea personal, ya sea profesional, el contratante en cuestión deberá ser considerado como consumidor si el objeto profesional no predomina en el contexto general del contrato, en atención a la globalidad de las circunstancias y a la apreciación de la prueba" ${ }^{12}$.

Ahora bien, aunque la sentencia se refiera a un contrato de préstamo con cláusulas abusivas ${ }^{13}$ este criterio podría

${ }^{11}$ STS, sala $1^{\text {a }}$, No $224 / 2017$, de 5 de abril de 2017 (JUR 2017/86709). Para un comentario véase: MARÍN LÓPEZ (2017).

${ }^{12}$ STS, sala $1^{\text {a }}$, No $224 / 2017$, de 5 de abril de 2017 (JUR 2017/86709).

${ }^{13}$ Sobre el punto véase $v . g r$. RodRílguez Achútegui (2016). 
ser aplicable a una más amplia tipología contractual en cuanto, al igual que el ordenamiento chileno, la definición del consumidor está insertada en un texto refundido. Por ello, podría relacionarse, incluso, con el hecho de que las ventas sean operadas, fuera o dentro de los establecimientos mercantiles y también a las celebraciones en los contratos a distancias.

\section{CONSUMIDOR Y CONSUMIDOR}

Al comparar el "núcleo" de las definiciones española y chilena ${ }^{14}$ de consumidor, se observa que el texto refundido de consumidores y usuarios español opta por un criterio definitorio a contrario de su cocontratante, identificando los consumidores con quien

“actúan en un ámbito ajeno a unaactividad empresarialo profesional ${ }^{15}$ ".

Esta es la definición según el texto refundido de 2007 que, bajo otros aspectos, ha recibido alguna modificación en $2014^{16}$

${ }^{14}$ Sobre la definición de consumidor $v . g r$. véase Momberg URIBe (2013), sobre la evolución de la definición a tenor de la ley $\mathrm{N}^{\mathrm{o}} 19.955$ de 2004 véase Pinochet Olave (2011).

${ }^{15}$ Véase art. 3 del texto refundido de la Ley General para la Defensa de los Consumidores y Usuarios (real decreto legislativo 1/ 2007 , de 16 de noviembre, $B O E$, No 287 , de 30 de noviembre de 2007 y sucesivas modificaciones).

${ }^{16}$ Con la reforma operada en 2014 se amplía aún más la definición de consumidor y se introduce una expresa apertura cuando se considera también como consumidor a aquellas personas jurídicas que "actúen sin ánimo de lucro en un ámbito ajeno a una actividad comercial o empresarial”. por la incorporación de la directiva $\mathrm{N}^{\mathrm{O}} 2011 / 83^{17}$.

La definición chilena toma, en cambio, un patrón más bien positivo, siendo consumidores

"adquieren, utilizan, o disfrutan, como destinatarios finales, bienes o servicios ${ }^{18 "}$.

Ahora bien ambas tienen en común que no prevén expresamente la hipótesis de multifinalidad que aquí se plantea.

$\mathrm{Al}$ ser diferentes las definiciones española y chilena, podría pensarse que los criterios y razonamientos de la sentencia recién mencionada no sirvan desde la perspectiva del ordenamiento chileno, sin embargo, no es así.

Efectivamente el contrato de préstamo fue celebrado antes de la entrada en vigor de la definición española recién mencionada. Por lo tanto, sería aplicable la definición de la Ley General del Consumidor, que ha inspirado ${ }^{19} \mathrm{la}$ actual conceptualización chilena y

Por el actual redacción del art. 3 RDlg. n. 1/2007, cit.: "A efectos de esta norma y sin perjuicio de lo dispuesto expresamente en sus libros tercero y cuarto, son consumidores o usuarios las personas físicas que actúen con un propósito ajeno a su actividad comercial, empresarial, oficio o profesión.

Son también consumidores a efectos de esta norma las personas jurídicas y las entidades sin personalidad jurídica que actúen sin ánimo de lucro en un ámbito ajeno a una actividad comercial o empresarial”.

${ }^{17}$ Directiva No 2011/83/UE del Parlamento Europeo y del Consejo, de 25 de octubre de 2011, sobre los derechos de los consumidores (DOCE L 304, de 22 de noviembre de 2011).

${ }^{18}$ Véase cfr. art. 1 ley $\mathrm{N}^{\mathrm{O}} 19.496$.

${ }^{19}$ Como ya ha destacado MOMberG URIBE, (2013), p. 4. 
que se fundamenta justo en consumidores que:

"adquieren, utilizan o disfrutan como destinatarios finales, bienes muebles o inmuebles, productos, servicios, actividades o funciones" $" 20$.

Por esto, la sentencia en comento es de particular interés, ya que, por un lado, se refiere a una definición que tiene los mismos fundamentos de la definición chilena y, por otro lado, porque su motivaciones se fundan en parte sobre el actual concepto de consumidor de origen comunitaria, es decir, el que se erige una definición negativa.

En definitiva, esto conduce a que, aunque de antitéticas posturas, la definición de consumidor que se construye 276 sobre patrones definitorios positivos y la que se basa sobre patrones negativos, son complementarias en cierto sentido.

\section{UTILIZACIÓN Y FINALIDAD}

Frente al silencio de la normativa comunitaria y nacional, el tribunal razona aportando un "considerando" de la directiva comunitaria y la jurisprudencia del Tribunal Superior de Justicia de la Unión Europea relativa a situaciones similares, como la compra de tejas por un agricultor para el tejado de una granja utilizada parcialmente para usos privados como para usos profesionales ${ }^{21}$;

${ }^{20}$ Véase la completa definición art. 1 Ley No 26/1984, de 19 de julio, General para la Defensa de los Consumidores y Usuarios (BOE, $\mathrm{N}^{\circ} 176$, de 24 de julio de 1984).

${ }^{21}$ STJUE de 20 de enero de 2005 , asunto C-464/01 (TJCE 2005/63), en relación con el o la del abogado que contrata un préstamo con garantía ${ }^{22}$; o la de los padres que afianzan la deuda de la empresa del hijo ${ }^{23}$.

Se orienta mediante el criterio del considerando $\mathrm{N}^{\circ} 17$ de la directiva $N^{o}$ 2011/83 que expresamente habla de doble finalidad del contrato ${ }^{24}$ y se orienta por la jurisprudencia señalada para acoger una definición de carácter objetivo que evalúa la funcionalidad por la cual se contrata. Así se establece:
"en aquellas circunstancias en las que existan indicios de que un contrato persigue una do- ble finalidad, de tal forma que no resulte claramente que dicho contrato se ha llevado a cabo

art. 13.1 Convenio de 27 septiembre relativo a la competencia judicial y la ejecución de resoluciones judiciales en materia civil y mercantil.

${ }^{22}$ Así, no tiene relevancia que la hipoteca que garantice el crédito fuese contratado como representante de un bufete de abogado. El sujeto sería consumidor al contratar sin haber especificado el destino del crédito y el contrato no está vinculado a su actividad profesional STJUE de 3 de septiembre de 2015, asunto C-110/14 (TJUE 2015/330), para un comentario véase ÁRROYO Aparicio (2016).

${ }^{23}$ ATJUE 19 de noviembre de 2015, asunto C-74/2015 (TJCE 2015/386)

24 "En el caso de los contratos con doble finalidad, si el contrato se celebra con un objeto en parte relacionado y en parte no relacionado con la actividad comercial de la persona y el objeto comercial es tan limitado que no predomina en el contexto general del contrato, dicha persona deberá ser considerada como consumidor" (considerando $\mathrm{N}^{\mathrm{O}} 17$, directiva No 2011/83, cit.). MARín LÓPEz (2017), p. 9 destaca que una redacción muy parecida se recoge en el considerando $\mathrm{N}^{\circ} 12$ de la directiva 2014/ 17/CE sobre los contratos de crédito celebrados con consumidores para bienes inmuebles. 
de manera exclusiva con un propósito ya sea personal, ya sea profesional, el criterio del objeto predominante ofrece una herramienta para determinar, a través de un examen de la globalidad de las circunstancias que rodean al contrato - más allá de un criterio puramente cuantitativo-y de la apreciación de la prueba practicada, la medida en quelos propósitos profesionales o no profesionales predominan en relación con un contrato en particular" 25 .

La sentencia, en consecuencia, incorpora la definición en relación con un objeto o fin predominante, mientras la postura operada por la jurisprudencia citada por la misma, se refiere terminológicamente a un criterio que más bien se relaciona con un uso marginal y no predominante, es decir, cambiando el enfoque de la perspectiva. Efectivamente antes se aludía al:

"uso profesional marginal hasta el punto de tener un papel insignificante en el contexto global de la operación de que se trate ${ }^{26 "}$.

La utilización de la referencia al fin predominante se ha criticado ${ }^{27} \mathrm{y}$

${ }^{25}$ STS, sala $1^{\mathrm{a}}$, n. $224 / 2017$, de 5 de abril de 2017 (JUR 2017/86709).

${ }^{26}$ STJUE de 20 de enero de 2005 , asunto C-464/01 (TJCE 2005/63), en relación con el art. 13.1 Convenio de 27 septiembre relativo a la competencia judicial y la ejecución de resoluciones judiciales en materia civil y mercantil.

${ }^{27}$ La doctrina no es favorable a esta solución, ya que afirma que la sentencia adopta el efectivamente puede conducir a una excesiva restricción del concepto de consumidor, aun cuando es importante destacar que la sentencia huya del criterio puramente cuantitativo.

Ahora bien, puesto que la sentencia se aplica en relación con una definición que es próxima a la chilena, frente a una definición relativa a un "destinatario final", seguramente para interpretarlafinalidad (sea esta preponderante o marginal) un buen análisis tomará como punto de referencia los patrones de "adquisición" y de "utilización" (cfr. art. 1 ley $\mathrm{N}^{\circ}$ 19.496) para valorar si estos son independientes entre sí y en qué medidas deben interpretarse.

La independencia de estos ha servido para discutir la aplicación de la normativa sobre consumo al consumidor material ${ }^{28}$; pero como puede percibirse debe ser asumido también a la hora de identificar el mismo concepto de consumidor jurídico.

El problema se complica aún más si se piensa que algunas tipologías empresariales son híbridas y justamente se caracterizan por entremezclar una actividad empresarial dentro de un ámbito que es más bien privado o familiar, como se legitima mediante la microempresa familiar, prototipo - mutatis mutandis- del caso aquí analizado.

\section{Bibliografía CITADA}

Árroyo Aparicio, Alicia (2015). "Abogado considerado como consumidor:

criterio del fin predominante que no exactamente coincide con la doctrina de STJCE de 20 de enero de 2005, MARÍN LÓPEZ, (2017), pp. 10-11. ${ }^{28}$ Barrientos Camus, (2013), p. 418. 
STJUE de 3 de septiembre de 2015, asunto C 110/14". Revista de Derecho Uned. $\mathrm{N}^{\circ}$ 19. Madrid.

Baraona González, Jorge (2015). "La nulidad de las clásulas abusivas en la Ley n. 19.946: un esquema de su naturaleza y régimen", en AA.VV. Estudios de Derecho Privado, homenaje al Profesor Ramón Domínguez Águila. Santiago: Thomson Reuters.

Barrientos Camus, Francisca (2013). “¿Por qué el consumidor debe ser el destinatario final de los bienes y servicios de manufacturación masiva?". Revista Chilena Derecho Privado. $\mathrm{N}^{\circ}$ 21. Santiago.

Camara Lapuente, Sergio (2017), "Doce tesis sobre la STJUE de 21 diciembre 2016: Su impacto en la jurisprudencia del TJUE y del TS,
Pinochet Olave, Ruperto (2011), "Delimitación material de Derecho de consumo: evolución de la noción de consumidor en la doctrina nacional", en AAVV, Estudios de Derecho Comercial. Santiago: Legal Publishing, Abeledoperrot.

Rodríguez Achútegui, Edmundo (2016). "La posición de los tribunales españoles respeto al concepto de consumidor amparado frente a cláusulas abusivas", Revista Aranzadi Doctrinal, $\mathrm{N}^{\circ}$ 5. Cizur Menor.

\section{Jurisprudencia citada}

Tribunal Superior de Justicia

de la Unión Europea

STJUE de 20 de enero de 2005, asunto C-464/01 (TJCE 2005/63).

STJUE de 3 de septiembre de 2015, asunto C-110/14 (TJUE 2015/330).

ATJUE 19 de noviembre de 2015, asunto C.74/2015 (TJCE 2015/386)

STJUE 21 de diciembre de 2016, asuntos acumulados C-154/15, C-307/15 y C-308/15 (TJCE 2016/309).

Jurisprudencia española

STS, pleno, No 241/2013, 9 de mayo (RJ 2013/3088)

STS, pleno, No 138/2015, de 24 marzo, (RJ 2015/845)

STS, pleno, No $139 / 2015$, de 25 marzo, (RJ 2015/735)

STS sala $1^{\text {a }}$, $\mathrm{N}^{\circ} 123 / 2017$, de 24 de febrero (RJ 2017/602)

Momberg Uribe, Rodrigo (2013), “art. 1", en Carlos Pizarro Wilson, Iñigo De la Maza Gazmuri (dirs.). Francisca Barrientos Camus (ed.). Derecho de los Consumidores. $2^{\mathrm{a}}$ ed., Santiago: Legal Publishing, Thomson Reuters.
STS sala $1^{\text {a }}, \mathrm{N}^{\mathrm{o}} 171 / 2017$, de 9 de marzo (RJ 2017/977)

STS, sala $1^{\mathrm{a}}, \mathrm{N}^{\mathrm{o}} 224 / 2017$, de 5 de abril de 2017 (JUR 2017/86709).

STS No 248/2017, de 20 de abril (RJ 2017/1559) 
SAP Vizcaya, sec. $4^{\text {a }}$, No 477/2014, de JPI mercantil, n. 1, Bilbao, No 249/2013, 30 de julio (JUR 2014/267776) de 10 de diciembre (AC 2014/175)

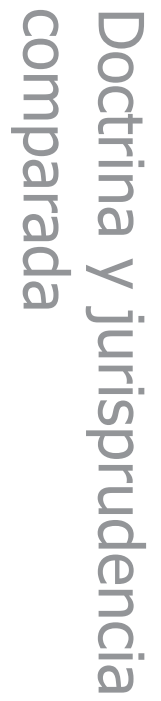

